\title{
PERAN SUPERVISI DALAM KONSELING
}

\author{
Satrio Budi Wibowo \\ email: satrio-budi@mail.ugm.ac.id \\ (Program Studi Bimbingan Konseling FKIP Universitas Muhammadiyah Metro)
}

\begin{abstract}
Abstrak : Proses supervise penting dilakukan dalam menjamin terselengaranya praktik konseling psikologis yang terstandar. Supervisi dilakukan oleh konselor yang berpengalaman (supervisor) kepada konselor yang masih baru (supervisee). Ketika proses supervise berlangsung, maka kegiatan konseling dan terapi psikologis yang diberikan oleh konselor sepenuhnya menjad itanggungjawab supervisor. Supervisor dapat membimbing supervisee dengan melewati proses real relationship, working alliance, dan transference. Supervisi yang baik akan mampu meningkatkan ketrampilan supervisor, sehingga layanan psikologis yang diberikan menjadi efektif dalam proses terapi klien.
\end{abstract}

\section{LATAR BELAKANG}

Perkembangan pesat dalam penggunaan konseling di Indonseia dalam beberapatahun terakhir, baik dalam setting klinis maupun pendidikan, berkaitan dengan meningkatnya kesadaran masyarakat dan ketertarikan media terhadap kegiatan terapi psikologis. Ketertarikan ini menciptakan kondisi kritis bagi pelaku konseling dan terapi. Persepsi masyarakat terhadap nilai-nilai konseling tergantung pada seberapa besar efektivitas konselor dalam menjaga standar kepuasan klien dalam prakteknya (Bond, dalam Wheeler, 2001). Wheeler juga menemukan bukti dalam penelitiannya bahwa programprogram pelatihan konseling tidak selalu berhasil mengeliminasi konselor-konselor yang tidak kompeten.

Perkembangan dalam permintaan layanan konseling menimbulkan konsekuensi terkait dengan tanggungjawab yang besar dan efektivitas biaya yang dikeluarkan klien. Menurut Parmer-Barnes (dalam Wheeler \& King, 2001), supervisi dan konsultasi dibutuhkan untuk memastikan terselenggarnya praktek konseling yang terstandar, dalam rangka untuk melindungi reputasi dari profesi. Lebih lanjut dikatakan bahwa kode etik tidak dapat menjamin standarisasi praktik konseling, karena kode etik hanya sebagai aturan moral, bukan operasional. Tuntutan akan efektivitas terapi dan treatmen adalah hal penting yang mengawali munculnya kebutuhan akan supervisi dan konsultasi, terutama bagi para konselor pemula.

Audit klinis (clinical Audit)baik berupa monitoring dan review dari konselor yang lebih berpengalaman merupakan cara untuk meyakinkan bahwa praktek konseling dilakukan sesuai standar. Jika kondisi psikologis klien diperiksa dengan tepat, kesalahan dan bias individual dapat direduksi. Dalam kerja klinis, ketrampilantingkat tinggi sangat diharapkan, hal ini untuk mengantisipasi agar konselor dan terapis dapat memberikan layanan dan perawatan yang lebih baik pada klien.

\section{TELAAH PUSTAKA}

\section{Pengertian Supervisi}

Menurut British Associations for Counselling and Psychoterapy (BAC) (Wheeler \& King, 2001), Supervisi diartikan sebagai suatu proses untuk menjaga standar konseling yang memadai dan suatu metode konsultasi dengan horizon yang lebih luas dari seorang praktisi yang berpengalaman.BAC juga mendefinisikan Supervisi sebagai suatu dukungan konsultatif dan menggambarkan hubungan 
antara supervisor dan konselor sebagai suatu hal yang menyediakan ruang bagi konselor untuk merefleksikan prakteknya.

Secara resmi dalam BAC Code of Ethics and Practice for Supervisors of Counsellors dirumuskan bahwa Supervisi adalah suatu proses kolaboratif yang bersifat formal dengan tujuan untuk membantu supervisee menjaga standar etika dan profesi dalam praktek konseling dan untuk mempertinggi kreativitas (BAC, dalam Wheeler $\&$ King, 2001).

Jenkins (dalam Wheeler \& King, 2001) menyatakan bahwa supervisi berasal dari bahasa latin, super dan videre, yang artinya melihat lebih jauh/lebih dalam (oversee). Fungsi hukumnya adalah untuk mengatur dan menyediakan sanksi formal bagi hubungan sosial yang luas. Kesulitan dalam menganalisa hubungan hukum dengan supervisi terapiutik adalah bahwa proses supervisi berisi sejumlah tipe-tipe hubungan profesional yang berbeda. Supervisi dapat berhubungan dengan beberapa hal dibawah ini :

- Clinical responsibility, tanggung jawab klinis dalam perawatan klien

- Professional responsibility, tanggung jawab profesional dalam kaitannya dengan seluruh kualitas pembuatan keputusan yang bersangkutan dengan klien

- Accountability, akuntabilitas dalam garis managemen dalam pembuatan keputusan bagi karyawan (dalam setting industri)

- Individual legal liability, tanggung jawab hukum secara individual dalam proses atau hasil perawatan klien

Jenkins (dalam Wheeler \& King, 2001) juga menyebutkan bahwa supervisor mempunyai serangkaian tanggungjawab etika terhadap klien yang ditangani oleh supervisee, yaitu memastikan bahwa kebutuhan klien terpenuhi, memastikan keselamatan dan kesejahteraan klien, melindungi kerahasiaan informasi personal klien (confidentiality of personal information) dan membuat perencanaan keberlanjutan perawatan klien dalam kondisi yang mendadak atau berakhirnya terapi yang tidak direncanakan.

\section{Tujuan dan Peran Supervisi}

Berikut tujuan dan peran supervisi bagi praktek konseling :

a) Untuk memfasilitasi perkembangan kompetensi terapiutik dari supervisee, dengan fokus perhatian pada hubungan terapis dan konselor (Taylor dalam Wheeler \& King, 2001)

b) Untuk memastikan bahwa klien mendapatkan konseling yang paling efektif; tugas supervisor adalah memonitor layanan yang diterima oleh klien (Caroll dalam Wheeler \& King, 2001)

c) Kadangkala menjadi penengah bagi konflik yang terjadi antara terapis/ konselor dan kliennya (Jones dalam Wheeler \& King, 2001)

d) Dalam institusi dan agensi, supervisi dijadikan sebagai alat untuk memastikan bahwa kebijakan-kebijakan klinis yang diberikan cukup membantu dan memberikan perlindungan dari pelayanan yang malpraktek (Jones dalam Wheeler \& King, 2001)

e) Untuk konselor yang berpraktek pribadi, supervisi dapat memastikan bahwa konseling yang dilakukan telah teruji dan terevaluasi (Syme dalam Wheeler \& King, 2001)

f) Sebagai proses pengembangan profesional yang berkelanjutan (BAC, dalam Wheeler \& King, 2001). Dalam hal ini Supervisi bukanlah suatu sanksi, karena bila supervisi dilihat sebagai sanksi yang mengendalikan dan 
mengatur kerja konselor, maka tujuan supervisi sebagai proses pengembangan profesional tidak tercapai.

\section{Proses Supervisi}

Seperti dijelaskan sebelumnya, Supervisi adalah sebagai proses dimana seseorang konselor yang berpengalaman (supervisor) memberikan bantuan kepada konselor yang kurang berpengalaman (supervise) untuk belajar konseling. Supervisi dilakukan pada konselor yang sedang magang atau baru bertugas, hingga konselor memiliki pengalaman yang cukup untuk melakukan konseling.

Menjalin hubungan antara supervisor dengan supervise merupakan hal yang penting dalam proses supervisi. Variabel-variabel yang terlibat dalam hubungan antara supervisor dengan supervise pada proses supervisi adalah, karakteristik kepribadian, macammacam pilihan, gaya, kebutuhan, dan langkah pengembangan professional (Lampropoulos, 2002).Hubungan yang baik antara supervisor dengan supervise saat proses supervisi membuat supervise dapat mengembangkan profesionalitas dan mengeluarkan secara maksimal pengalaman supervisinya. Terdapat tiga proses dalam supervisi, yaitu hubungan yang sebenarnya (real relationship), kerjasama (working alliance), transfer ketrampilan (transference). Lebih lanjut Gelso \&Carter (Lampropoulos, 2002) menjelaskan secara rinci ketiga proses dalam supervisi di atas sebagai berikut :

\section{The real relationship}

Konsep dasar dari hubungan supervisi yang sebenarnya (atau lawan kata dari tidak sebenarnya / unreal, dikesampingkan dari proses transfer), adalah konsep kondisi Rogerian (empati, kehangatan /keramahan, tidak berpura-pura, penghargaan tanpa syarat), termasuk juga variabel-variabel seperti keterampilan-keterampilan dan kualitas pribadi supervisor dan supervisee, penyingkapan diri (self-disclosure), kepercayaan, dan pengaruh sosial. Aspekaspek dasar di atas amat penting, terutama sekali bagi para konselor baru (Bernard \&Goodyear, 1998). Berempati pada kesulitan yang dihadapi trainee pada tiap tahap dari perkembangan menjadikan proses supervise lebih efektif. Sebaliknya, penghargaan tanpa syarat dapat menjadi ancaman, karena supervise termasuk satu proses yang evaluatif. Meski evaluasi terhadap supervisee perlu (karena para supervisor merupakan penjaga dari profesi), akan tetapi hal tersebut dapat merusak proses terjalinnya kerjasama dalam supervisi. Hasil riset menunjukkan bahwa proses evaluasi sebagai suatu katalisator supervisor dalam menjalin kerjasama (Burke, Goodyear, \& Guzzard, 1998).

Dalam proses supervisi, supervisor walupun memiliki tugas utama membimbing supervisee, akan tetapi perlu diciptakan hubungan yang lebih bebas agar supervisee dapat berkembang dan menjadi tipe konselor sesuai dengan diri mereka/harapan mereka. Pada tipe supervisi yang berpusat pada trainee (supervisee), trainee (supervisee) dapat mengembangkan profesionalitas diri mereka sesuai dengan diri mereka/harapan mereka sendiri, yang akhirnya akan meningkatkan efikasi diri mereka sebagai konselor. Pada tipe supervisi yang berpusat pada supervisor, supervisor harus mampu mempengaruhi supervisee agar dapat diterima sebagai seorang guru yang mahir atau orang yang sangat ahli, sehingga proses supervise sepenuhnya dikuasai oleh supervisor, sehingga tercipta hubungan yang tidak bebas akan tetapi lebih terarah dalam proses transfer ketrampilan. 
2. Working alliance (contract, goals, task) / Aliansi kerja (membuat kontrak, sasaran, dan menyusun tugas)

Konsep trans teori tentang kerjasama yang berada (-yaitu.,ikatan, sasaran dan tugas) di dalam konseling diperkenalkan di supervise oleh Bordin (1983). Akhir-akhir ini konsep kontrak (dalam konseling atau supepervisi) berada di dalam konsep kerjasama dan konsep ikatan berada dalam konsep hubungan yang nyata (real relationship). Penting untuk diingat, pembedaan ini tidak tetap dalam menguraikan proses konseling dan intervensi. Sebenarnya, semua konsep di atas berhubungan erat dan secara terusmenerus saling berhubungan antara satu sama lain (lihat juga Constantino, Castonguay, \& Schut, 2001).

Kontrak supervise antara kedua peserta, untuk memberikan supervisi (supervisor) dan mendapatkan supervisi (supervisee) harus ditetapkan dengan mempertimbangkan keuntungan yang didapatkan, respek, ikatan dan hubungan. Dari awal, kontrak ini harus rinci dan jelas, dan mendapatkan feedback dari kedua belah pihak, dimana supervisor sebagai seorang ahli harus bertanggungjawab terhadap proses serta hasil akhir dari supervisi.

Sasaran (goals) supervise terdiri dari: (a) penilaian atas kekuatan-kekuatan dan kelemahan supervisee, begitu pula terhadap kebutuhan-kebutuhan dan pilihan-pilihan mereka yang spesifik, dan (b) penentuan dari ketrampilan-ketrampilan yang spesifik yang akan dipelajari dan dikuasai. Ketentuan dalam membuat sasaran ini didasarkan pada kebutuhan spesifik dari supervisee, pilihanpilihan,dan tahap perkembangan.

Tugas (task) disusun untuk menjangkau sasaran di dalam supervisi, merupakan salah satuhal yang penting. Proses menetap kan tugas (task) antara lain menetapkan struktur, bimbingan, instruksi, umpan balik dan evaluasi yang dilakukan oleh supervisor, seperti juga evaluasi diri, latihan dan aplikasi pengetahuan dan ketrampilan-ketrampilan yang baru, tindakan korektif, dan eksplorasi alternatif-alternatif yang dilakukan oleh supervisee.

\section{Transference and Countertransfer- ence / Transfer dan feed back}

Suatu derajat distorsi dan bias di dalam intervensi, sebagai dampak dari proses pemindahan (transference) dan feedback dari proses pemindahan (countertransference) (Bernard \& Goodyear, 1998). Situasi dapat menjadi lebih rumit lagi sebagai hasil dari proses paralel, di mana supervisee secara simultan berposisi sebagai konselor dan supervisee. Proses pemindahan merupakan proses dimana supervisor mengajarkan atau mentransfer ketrampilan yang dimilikinyakepada supervisee.

Watkins (1995b) menemukan adanya perilaku patologis di dalam proses supervisi (seperti, kecemasan, kepercayaan pada diri sendiri yang kompulsif, perhatian yang kompulsif) dan menjelaskan mengapa supervise gagal pada kasus tertentu. Meski Watkins mengakui hal ini jarang terjadi dalam mempengaruhi kelulusan program supervisi. Bahkan ketika supervisor mengkritisiti pekonseling yang diterapkan supervisee dalam konseling, supervisor perlu menjalin hubungan sebagai usaha untuk mengerti kebutuhan trainee, sehingga menghasilkan proses pembelajaran yang optimal dalam proses supervisi.

Cara supervisee dapat mengikuti teori belajar, disini supervisor membantu supervisee dalam upaya meningkatkan pengetahuan. Misalnya teori dinamik memperhatikan 
perubahan-perubahan emosi yang mendasari yang terjadi antara klien dan supervisee. Supervisi disini mencakup eksplorasi aktivitas subkonsius klien. Perhatian khusus diberikan pada reaksi tidak sadar klien terhadap supervisee dan perasaan-perasaan klien yang dipindahkan secara tidak realistik terhadap supervisee. Supervisi membantu supervisee mengerti dan menghadapi perasaan yang ditransfer tersebut.

\section{KESIMPULAN}

Berdasar uraian di atas, dapat disimpulkan bahwa supervise berperan penting dalam menjaga standarisasi praktik konseling di masyarakat. Organisasi profesi konseling psikologis di Indonesia baik HIMPSI (Himpunan Psikologi Indonesia) yang memayungi para ahli Psikologi dan ABKIN (Asosiasi Bimbingan Konseling Indonesia) yang memayungi para konselor, hendaknya menerapkan layanan supervise dengan sesungguhnya. Penerapan proses supervisi yang serius tentunya dapat mencegah terjadinya praktik konseling yang dibawah standar. Karna praktik konseling yang dibawah standar akan memberikan dampak negative terhadap kepercayaan masyarakat pada praktik konseling psikologis.

\section{REFERENSI}

Blocher, Donald H., Donald A. Biggs. 1983. Counselling Psychology in Community Settings. Springs Publishing Company.

Gladding, Samuel T. 2000.Counselling. New Jersey : Merrill.

Henderson, Patricia, Norman C.Gysbers.Providing Administrative and Counseling Supervision for School Counselors. Articles. Hhtp//www. diakses

Hershensen, David B., Power, Paul W., Waldo Michael. 1996. Community Counselling.Boston : Allyn and Bacon.

Lampropoulos, Georgios K. A Common Factors View of Counseling Supervision Process. The Clinical Supervisor, Vol. 21(1), 2002.

Wheeler, Sue, David King. 2001. Supervising Cousellors. Issues of Responsibility. London : Sage Publications.

Woody, Robert Henley, James C. Hanger, Robert H. Rossberg. 1989. Counselling Psychology. Strategies \& Services.California : Brooks/Cole Publishing Company. 